\title{
Indirect improvement of pearl grade and shape in farmed Pinctada margaritifera by donor "oyster" selection for green pearls
}

\author{
Chin-Long Ky ${ }^{a}{ }^{*}$, Carole Blay ${ }^{a}$, Manaarii Sham-Koua ${ }^{a}$, Cédrik Lo $^{b}$, Philippe Cabral ${ }^{c}$
}

\author{
a Ifremer, UMR 241, EIO, Labex Corail, Centre du Pacifique, BP 7004, 98719 Taravao, Tahiti - Polynésie \\ Française \\ ${ }^{\mathrm{b}}$ Direction des Ressources Marines et Minières, BP 20, 98713 PAPEETE, TAHITI - Polynésie Française \\ ${ }^{c}$ Gauguin's Pearl Farm, BP 191, Avatoru, Rangiroa - Archipel des Tuamotu, Polynésie Française \\ *: Corresponding author : Chin-Long Ky, email address : chinky@ifremer.fr
}

\begin{abstract}
:
The top aquaculture species in French Polynesia is Pinctada margaritifera, a mollusc grown for the production of a unique gem: the black pearl. One of the challenges facing the pearl farming industry is to "produce less but better pearls" through genetic improvement. An experimental hatchery system was used to generate full-sib families to be tested for their potential as donor "oysters". A large-scale grafting experiments was done and seven cultured pearl quality traits: grade, surface defects, lustre, darkness level, visual colour categories, circles and shape categories were recorded. Our results revealed, for the first time, significant phenotypic relationships between these quality traits. The grade A cultured pearl class had the largest proportion of pearls with a green overtone (65\%), the lowest number of circled pearls (15\%) and the maximum of round-shaped pearls (45\%). In contrast, the "reject" cultured pearl class had the largest proportion of pearls with grey bodycolor (65\%), the greatest number of circled pearls (35\%) and the maximum with a baroque shape (nearly $60 \%$ ). When grade components were studied separately, cultured pearls in the zero surface defect class exhibited the same tendencies as grade A pearls, contrasting with the class where there were more than ten defects on the surface of each pearl. When cultured pearls were classified according to the presence or absence of lustre, pearls with lustre mostly had a green overtone colour, while pearls without lustre did not. These findings have major implications for cultured pearl quality improvement, as modern genetic breeding methods can increase the proportion of high quality cultured pearls though selected lines of donor oysters capable of producing pearls with a green overtone. Selection of appropriate donor phenotypes, incorporation of pigmentation traits into a pearl oyster breeding program and production of lines with desirable colours will be developed for oyster aquaculture in French Polynesia.
\end{abstract}

\section{Highlights}

- Correlation between pearl grade with colour and shape exist in P. margaritifera. Grade A pearls was related to green overtone, round shape and uncircled pearls. Pearls in reject class was related to more grey bodycolor and circled pearls. Selection for green/peacock pearl increase the grade A pearls rate.

Keywords : pearl "oyster" ; Pinctada margaritifera ; donor "oyster" ; cultured pearl quality ; pearl grade ; pearl colour ; pearl shape ; selective breeding 


\section{Introduction}

In French Polynesia, the marine bivalve mollusc Pinctada margaritifera var. cumingi is the top aquaculture species, far ahead of the two main food species: blue shrimp, Litopenaeus stylirostris (70 tons produced in 2012) and the lagoon fish Platax orbicularis (20 tons produced in 2012). In fact, the pearl culture industry plays a major economic role and represents the largest export industry in the region. The market for pearls increased from 86 $\mathrm{kg}$ in 1980 to 16 tons in 2012 (7.7 million cultured pearls), representing nearly 65 million euros in export value (customs statistics, Wane, 2013). The pearl culture industry employs near 5000 people, on 487 farms, occupying approximately 7800 ha across 25 atolls and islands of French Polynesia (2013 data from "Direction des Ressources Marines et Minières", Tahiti). From a biological point of view, Pinctada margaritifera inhabits subtropical and tropical coral reefs, and is widely distributed in the Indo-Pacific area, down to Northern Australia throughout the Equator extending up to the southern region of Japan (Le Pennec et al., 2010). This mollusc is also known as the black-lip pearl "oyster" (usual term to qualify this mollusc, which is not an oyster) due to the dark marginal colouration of the mantle. In French Polynesia, the exploitation of natural stocks of this abundant mollusc is made for the production of cultured pearl of gem quality. The cultured pearl grafting procedure consists in introducing a nucleus (beads made from a fresh-water bivalve shells) and a graft (a piece of mantle from a selected donor "oyster") into the gonad of a recipient "oyster". Before they are ready to be harvested, pearls take 15 to 24 months of culture to form as their successive layers form around the epithelial cells implanted in the recipient "oysters" along with the nucleus.

The quality of Tahitian cultured pearls is assessed visually by the naked eye (with no magnification device such as a jeweler's loupe) according to an official A-D classification (Journal Officiel $2001 \mathrm{n}^{\circ} 30,26$ July 2001). This grading system takes into account two physical parameters: 1) the perfection of the surface and 2) its lustre. Tahitian cultured pearls can be defined into five grades: 1) Top Gem: a perfect cultured pearl, with an excellent lustre; 2) grade A: surface without imperfections on $90 \%$, with a very beautiful lustre; 3 ) grade B: smooth surface on $70 \%$, with a good lustre at the minimum; 4) grade C: smooth surface on $40 \%$, with a medium lustre at the minimum; and 5) grade D: weak lustre with small imperfections on more than $60 \%$. Under Tahitian government regulation, cultured pearls below D quality cannot be exported from Tahiti, but they can be sold locally. The surface quality can be judged by diverse imperfections such as dimples, bumps, stripes, curls, grooves, organic deposits, swellings, growths or milky discoloured spots. The lustre, or shine, 
refers to the more or less perfect reflection of light from the surface of the pearl. It depends on the regularity, the thickness and the arrangement of the layers of nacre. A beautiful lustre is the result of a total reflection of light, which gives a mirror-like effect. A cultured pearl without lustre looks dull.

P. margaritifera cultured pearls have a wide range of colours, from the purest white to the deepest black, and could have a combination of body and secondary colour, passing through every shade of silver, peacock green, aubergine purple, golden browns and even rainbows, which can be used to make characteristic multicoloured necklaces. So, the commercial name is misleading, as the "Black Tahitian Pearls" are far from being all black. The colour is generally linked with their commercial value: the darker a P. margaritifera cultured pearl is, the more valuable it is. Cultured pearl colour varies according to the original graft made when the nucleus was inserted, and depends mainly on the donor "oysters" (Tayale et al, 2012). The predominant bodycolors of $P$. margaritifera cultured pearls are grey, yellow and white. $P$. margaritifera cultured pearls also have attractive overtones (secondary colours): green, aubergine (reddish purple) and peacock. These overtones may be present in a variety of combinations and are considered a plus factor. Tayale et al. (2012) and Ky et al. (2013) demonstrated significant donor and family effects, respectively, on pearl darkness level, using individual wild donors and hatchery-bred families. A completely black pearl with no overtone is considered less desirable and may be worth $50 \%$ less than one of similar quality with green overtones. Shape is one of the principle determining factors of a cultured pearl's value. With all other factors being equal, the general rule is that the rounder the pearl, the more valuable it is. Cultured pearls come in a wide variety of shapes, each having a specific designation. Tahitian pearl technicians sort black pearls into five different shapes: round, semi-round, semi-baroque, ringed or circled and baroque. Circled pearls generally account for $25-30 \%$ of a Tahitian cultured pearl harvest. To date, there have been no studies published examining the shapes of cultured pearls from P. margaritifera.

Despite the importance of Pinctada sp., very little is known about the correlations between important cultured pearl quality traits. In $P$. fucata, the phenotypic correlations between pearl weight and colour have been studied (Velayudan et al., 1996, Wada, 1984, and Wada, 1986). Correlations between quality traits has been examined in a xenograft system between P. maxima and P. margaritifera (McGinty et al., 2010). In P. margaritifera, the influence of nacre deposition rate (nacre thickness and weight) has been studied in relation to 
cultured pearl grade and colour (Blay et al., 2014). A genetic programme focused on the donor "oyster" has been initiated at the Ifremer (French research institute for the exploitation of the sea) research centre in Tahiti (French Polynesia) in collaboration with the Direction des Ressources Marines et Minières (DRMM). The main aim of the programme is to establish selected lines of donor "oysters" for several cultured pearl quality traits. Several first generations (G1) families of donor "oysters" have already been produced in both the Ifremer and DRMM hatcheries. The main objective of the present study was to test some full-sib families in a standardised single-site experimental grafting design, in order to evaluate their potential as donor "oysters", estimate the family effect on cultured pearl quality traits and study the relationships between these traits. We report the significant relationships observed between cultured pearl classification grade and its components (surface and lustre) on pearl colour and shape, using 15 full-sib families. In a context of overproduction, world economic crisis and competition from other cultured pearl producing countries, this study constitutes a step towards the application of modern genetic breeding programs in French Polynesian pearl production, in which the main challenge will be to produce less pearls, to reduce impact of the industry on the environment, but to obtain a better quality product. 


\section{Materials and methods}

\section{1 Full-sib family production}

Fifteen bi-parental families were produced in the Ifremer hatchery (Tahiti, French Polynesia) by breeding fifteen female and fifteen male broodstock "oysters". Spawning was triggered by thermal shock according to Ky et al. (2013). To minimize the risk of cross contamination, oocytes were thoroughly rinsed out of the mantle cavity of the spawning females. Each female was then placed into an individual spawning tray where it continued to release fresh oocytes that had not come into contact with sperm. These oocytes were then cleaned through an $80-\mu \mathrm{m}$ sieve and washed on a $25-\mu \mathrm{m}$ sieve. A verification of sperm motility was carried out for each male. Oocytes were then fertilised at a ratio of 5-10 spermatozoa per oocyte. The fertilisation rate was evaluated in triplicate 3 hours later according to the methodology used for seabass fertilisation rate estimation by Ky et al. (2012).

\section{2 Larval rearing, settlement, pre-growing}

Fertilized eggs were put into an incubator with $1-\mu \mathrm{m}$ filtered seawater held at $28^{\circ} \mathrm{C}$. After $24 \mathrm{~h}$, the D-shaped larvae were collected on $45-\mu \mathrm{m}$ screens, and each family was reared separately in a through-flow culture system (Hui et al., 2011). D-shaped larvae were fed for 10 days on two tropical microalgae species: Isochrysis galbana (clone T-iso) and Chaetoceros var. "minus". Then, from the 11th day, they were fed on a mix of three microalgae (I. galbana, C. minus, and Chaetoceros gracilis) (Ky et al., 2013). One month after the appearance of eyed-larvae, the seed "oysters" were pregrown to reach a size higher than 5 $\mathrm{mm}$. The juveniles were detached once they reached an average size of $20 \mathrm{~mm}$ and were transferred to the natural environment where they were grown in Aquapurse ${ }^{\circledR}$ plastic trays. The pearl "oysters" were reared for 2 years in these Aquapurse ${ }^{\circledR}$ trays, suspended on long lines located in the lagoon of Vairao. They were maintained at a depth ranging between 6 and 10 metres. For better management of individuals, the mesh size of the trays was varied according to their size. The baskets were cleaned every 3 months, as were the animals.

\section{3 Experimental animals and grafting procedure}

At the age of 34 months (average shell size of $10 \mathrm{~cm}$ ), ten individuals were randomly selected from each of the fifteen G1 families (named with the numbers1-15) and labelled. These 150 "oysters", which would serve as donors, were transferred to Rangiroa atoll 
(Tuamotu Archipelago). Here, they were reared for two months prior to the grafting campaign, which was carried out at Gauguin's Pearl farm facilities. The donors were used to make 2250 grafts, which were performed over 5 days (15 families x 10 donors per family x 15 grafts per donor $=2250$ grafts). As a way to minimize grafter effect on cultured pearl quality traits, a single professional grafter performed all the grafts in this experiment. Thirty donor "oysters" were randomly selected per day for the grafting procedure. A second grafter, who assisted the first one, worked exclusively on the excision of the fifteen graft pieces from the mantle edge valves of each donor, following standard pearl farm procedures. All receiving pearl "oysters", issued from a single natural spat collection, were selected based on visible health status (colour of the visceral mass and gills), shell size and appearance, and muscle resistance when the shells were pried open. Each receiving mollusc was grafted using a 2.4 BU nucleus (7.304 mm diameter, $0.59 \mathrm{~g}$ weight - Nucleus Bio, Hyakusyo Co. Japan). After grafting, the receiving "oysters" were placed in separate net retention bags, which had a mesh size allowing rejected nuclei to be caught. Nucleus rejection (presence of the rejected bead in the bags, i.e., outside the molluscs)and receiver mortality were evaluated at 45 days after the graft operation. The labelled pearl "oysters" that had retained their grafted nucleus (no bead detected in the bags) were drilled and fixed on long-lines after removing the net retention bags. Cultured pearls were harvested 18 months after grafting.

\section{4 Measurement of cultured pearl quality traits}

Cultured pearls were cleaned by ultrasonication in soapy water (hand washing) with a LEO 801 laboratory cleaner ( 2 L capacity, $80 \mathrm{~W}, 46 \mathrm{kHz}$ ); they were then rinsed in distilled water.

Cultured pearl grade for each sample was determined by a single professional expert from Maison de la Perle, according to the official Tahitian classification (Journal Officiel $2001 \mathrm{n}^{\circ} 30,26$ July 2001). A cultured pearl grade was thus attributed to each pearl, from the most valuable quality to the least: A, B, C, D and rejects (rebuts). Briefly, the five grades are mostly based on surface purity and lustre:

- $\quad$ A, cultured pearls showing no surface defects or small defects confined to less than $10 \%$ of their surface and having very good lustre;

- $\quad$ B, cultured pearls showing defects distributed over less than one third of their surface and having good or medium lustre; 
- $\quad$ C, cultured pearls showing defects distributed over less than two thirds of their surface and having medium lustre; and

- $\quad$ D, cultured pearls showing many very visible defects over more than two thirds of their surface and having poor lustre.

- $\quad$ Rejects are cultured pearls that have too many defects to be graded; they are consequently discarded and ultimately destroyed.

Surface defects and lustre (components of cultured pearl grade) were determined visually (without a jeweller's loupe) and separately so that they could be studied independently, by two operators working in cooperation. Visible sample surface defects (checked all over the surface sample) including pits, bumps, scratches, deposits or other surface flaws were counted visually (without a loupe) and each cultured pearl was then classified into one of four categories: no defects, 1 to 5 defect(s), 6 to 10 defects and over 10 defects. Cultured pearl lustre was evaluated by scoring pearls according to their presence of lustre (glossy and shiny) or its absence (matte appearance).

Two kinds of colour evaluation (without a jeweller's loupe) were made on the cultured pearls (Ky et al., 2013) by two operators working in cooperation:

- $\quad$ Darkness of colour, with three categories depending on its level: high, medium and low;

- Visually-perceived colour category, which is due to pigments (bodycolor), and secondary colour (overtone). Six "colour categories" were constituted into which all the harvested pearls could be classified: 1) samples with dominance of bodycolors (without overtone): grey, white and yellow, and 2) samples with addition of secondary colours (moderate to distinct overtones): green, aubergine (red / purple), and peacock (a mix of aubergine and green).

- $\quad$ Cultured pearl shape was determined by both of the operators (in the same way as surface defects, lustre, darkness and colour) and was characterized in two ways:

1. The presence/ absence of circle/s on the cultured pearls, whatever the shape category;

2. The shape, for which there were three categories: 1) "R", for round or semiround shapes (sphere with a variation in diameter between $2 \%$ and $5 \%$ ); 2) "O", for oval, button and drop shapes (diameter variation $>5 \%$, with a 
symmetrical axis); and 3) "B", for baroque pearls, which have no definite shape (irregular) and are asymmetrical.

\section{5 Statistical analysis}

Differences in nucleus retention rate among the fifteen donor families were evaluated using chi-square tests. Kruskall-Wallis tests were used to test for differences in nacre thickness and weight among the donor families (Siegel and Castellan, 1988). If the overall test was significant, a Dunn procedure with a Bonferroni correction was performed among all pairs of donors (Winer et al., 1991).

Qualitative classes based on cultured pearl surface defects, lustre, grade, darkness and circles were re-encoded to give quantitative scores that would enable the mean value of families to be obtained for each variables, thus allowing them to be ranked. Scores from 0 to 4 were attributed to the different classes from the least to the most valuable (with grade, surface defects, darkness and lustre), as detailed in Ky et al., 2013. Due to non normality of the variable distributions, non parametric Kruskal-Wallis tests were used to test for differences among the families.

For the cultured pearl colour categories and shape categories, differences between families and effect of family were evaluated using chi-square tests.

To test within each cultured pearl grade, surface defect or lustre categories, the independence with the other quality traits (darkness level, colour categories, presence or absence of circle and shape), the Chi-square test were performed.

We compare inter-grade, inter-surface defect or inter-lustre level independence with each level of other quality traits (darkness level, colour categories, presence or absence of circle and shape) using Fisher's exact test (represented by letters in each figures).

In all tests, $p$-values lower than 0.05 were considered significant (Dagnelie, 2006). All analyses were performed using XLSTAT (version 2009.4.02) and R software (version 2.14.1). 


\section{Results}

\subsection{Full-sib family effects}

Among the 2250 grafts, the proportions of nucleus retention, nucleus rejection and "oyster" mortalities were $75.5 \%, 18.8 \%$ and $5.7 \%$, respectively, at 45 days post-operation. Among the 1699 "oysters" that retained their nuclei, 1342 cultured pearls and 63 keshis (nonbead cultured pearl that provide from "oysters" that rejected their nucleus during the culture period) were harvested. Highly significant donor family effect was found for nucleus retention, nucleus rejection and "oysters" mortalities $(p<0.001)$.

Table 1 summarizes the cultured pearl quality data scored on pearls produced from the fifteen full-sib donor families. For each of the seven quality traits (classification grade, and surface defect, lustre, visual colour, darkness level, circle and shape categories), very highly significant effects were recorded among the full-sib families $(p<0.0001)$. For classification grade, family 2 showed the highest proportion of grade A pearls, whereas no grade A pearls were found in family 13 . For surface defect traits, $22 \%$ of family 6 pearls had no surface defects, whereas all pearls in family 7 had at least one defect. For lustre, family 7 contained $97 \%$ of pearls with lustre, whereas family 10 had the smallest percentage, with $71 \%$ of pearls with lustre. For the green pearl overtone colour, families 7 and 1 represented the extremes, with $70 \%$ and $21 \%$, respectively. The highest proportion of dark toned pearls was found in family 11 where they represented $36 \%$, and the lowest proportion was in family 1 , where there were only $2 \%$. Family 7 shows the highest proportion (85\%) of un-circled pearls, whereas there were only $55 \%$ in family 4 . The highest rate of round and semi-round pearls was found in family 13 , with $58 \%$, and the lowest proportions were found in families 4 (34\%), $7(45 \%)$ and $12(34 \%)$.

\subsection{Relation between cultured pearl grade and darkness or colour categories}

The 1342 harvested pearls were distributed as follows among the five classification grades: grade A: $8.8 \%(N=118)$, grade $\mathrm{B}: 21.8 \%(N=293)$, grade $\mathrm{C}: 32.9 \%(N=441)$, grade D: $24.0 \%(N=322)$, and rejects: $12.5 \%(N=168)$.

As a whole, the harvested pearls were divided among the three darkness levels as follows: low: $25.6 \%(N=344)$, moderate: $52.4 \%(N=703)$, and high: $22.0 \%(N=295)$. Figure 1a shows how the three darkness levels were represented for each pearl grade. Within 
each pearl grade, the amount of pearls in each darkness level showed a very highly significant difference: $p<0.0001$ for grades A, B, C, D and rejects. Among the different grades, the high darkness level accounted for significantly different proportions of pearls $(p=0.001)$, but such differences were not significant for the low $(p=0.128)$ and moderate darkness levels $(p=$ 0.260). For the high darkness level, reject class was not significantly different from grade B (letters "ab" on figure 2a).

Six visual colour categories could be clearly distinguished among the harvested pearls: green $(N=702 ; 52.3 \%)$, peacock $(N=84 ; 6.3 \%)$ and aubergine $(N=54 ; 4.0 \%)$ as secondary colours; and grey $(N=412 ; 30.7 \%)$, yellow $(N=59 ; 4.4 \%)$ and white $(N=31 ; 2.3 \%)$ as bodycolors. The bar chart in figure $1 \mathrm{~b}$ shows the contributions of these six colour categories within each pearl grade category. A very highly significant effect was found among the proportions of pearls in the different colour categories within each pearl grade: $p<0.0001$. Among cultured pearl grades, no significant difference was recorded for the proportions of: 1) the two bodycolors yellow ( $p=0.956)$ and white $(p=0.474)$, or 2$)$ the secondary colour aubergine $(p=0.658)$. For the same inter-grade comparison, a very highly significant difference $(p<0.0001)$ was recorded for: 1$)$ two the secondary colours green and peacock and 2 ) the grey bodycolor. Among these last three colour categories, gradients were observed following the cultured pearl quality grade classification, from best to worst: the amounts of green and peacock pearls decreased, whereas the amount of grey pearls increased. Indeed, green cultured pearls represent approximately $2 / 3$ of the grade A pearls. Conversely, the proportion of green cultured pearls in the reject grade was nearly three times less than in the grade A class. The opposite situation was observed for grey bodycolor, which represented approximately $2 / 3$ of the reject grade, in comparison with grade A pearls, in which only $12 \%$ were grey. Pearls with peacock secondary colour represented $12 \%$ of grade A pearls but only $1 \%$ of the reject grade.

\subsection{Relation between cultured pearl grade and circle or shape}

Presence or absence of circles on cultured pearls was evaluated among the 1342 harvested samples. Cultured pearls with and without circles represented $27 \%(N=358)$ and $73 \%(N=984)$, respectively. Figure 2a shows the ratios of pearls with and without circles within each pearl grade. A very highly significant effect was recorded for the presence or absence of circles $(p<0.0001)$ within each pearl grade. Comparison among the pearl grades revealed a highly significant effect for the presence or absence of circles $(p<0.0001)$. 
Approximately $85 \%$ of grade A-B pearls had no circles; whereas only $65 \%$ grade D-reject pearls had none. Grade D-reject pearls grades therefore contained about $25 \%$ more circled pearl than grades A-B.

For pearl shape categories, the 1342 scored samples were distributed among the three shape categories as follows: $45 \%(N=598)$ of R shape, $43 \%(N=584)$ of B shape and $12 \%$ $(N=160)$ of $\mathrm{O}$ shape. Figure $2 \mathrm{~b}$ shows the amount of the three shape categories in each pearl grade. Intra pearl grade comparison reveals a very highly significant difference among the proportions of the different shape categories $(p<0.0001)$. Among the cultured pearl grades, the proportions of the three shape categories were highly significantly different for B shape ( $p$ $<0.0001)$ and $\mathrm{R}$ shape $(p=0.005)$, but were not significantly different for $\mathrm{O}$ shape $(p=$ $0.159)$. Grade A category had $46 \%(N=54)$ of R pearls, $36 \%(N=43)$ of B pearls and $18 \%$ $(N=21)$ of O pearls. In contrast, reject grade had $33 \%(N=56)$ of $\mathrm{R}, 58 \%(N=98)$ of $\mathrm{B}$ and $8 \%(N=14)$ of O pearls. For R shape, grade A, B and C pearls showed the largest proportion, with nearly $50 \%$ of this category, whereas the reject class, which is significantly different from the other grades, showed the smallest proportion.

\subsection{Relation between cultured pearl surface defects and darkness or colour categories}

The 1342 harvested pearls were distributed among the four pearl surface defect categories as follows: $8.9 \%(N=119)$ of pearls without any defects, $51.0 \%(N=685)$ with 1 to 5 defect(s), $30.2 \%(N=405)$ with 6 to 10 defects and $9.9 \%(N=133)$ more than 10 defects. The different proportions of the darkness levels according to surface defect category are shown in figure 3a. Intra pearl surface defect category comparisons showed a very highly significant difference among the different darkness levels in all surface defect categories $(p<$ 0.0001). Among pearl surface defect categories, proportions of the high darkness level were very highly significantly different $(p<0.0001)$, but those of the low $(p=0.069)$ and moderate $(p=0.179)$ darkness level were not.

Figure $3 \mathrm{~b}$ shows the proportions of the six colour categories in each of the four surface defect groups. Within each pearl surface defect group, the proportions of colour categories were very highly significantly different: $p<0.0001$. Among the pearl surface defect groups there was no significant difference for the percentage of pearls with aubergine secondary colour $(p=0.913)$ or for those with white $(p=0.806)$ or yellow $(p=0.118)$ bodycolor. At the same scale of inter-group comparison, however, very highly significant differences $(p<$ 
0.0001) were found for proportions of green secondary colour and grey bodycolor, and a highly significant difference was found for peacock secondary colour $(p=0.003)$. A gradient was observed according to the pearl surface quality groups for green, grey and peacock pearls: from the best surface defect group to the worst, the amounts of green and peacock secondary colour pearls decreased, whereas the amount of grey bodycolor pearls increased. The 0 defect group contained $60 \%$ of green and $7 \%$ of peacock pearls. The category with over 10 defects per pearl had $24 \%$ of green and $0 \%$ of peacock pearls. In contrast, grey bodycolor accounted for $25 \%$ of the 0 defect category and $66 \%$ of the category with over 10 defects.

\subsection{Relation between the number of surface defects and presence of circles or pearl shape}

Incidence of circles among the surface defect classes is illustrated in figure 4a. Within each surface defect category, a very highly significant effect was recorded for the presence or absence of circles $(p<0.0001)$. Inter cultured pearl grade comparison also revealed a highly significant effect for the presence or absence of circles $(p<0.0001)$. In the category of pearls with less than five defects ( 2 categories), an average of $81 \%$ had no circle, whereas only $62 \%$ of those with more than six defects (two categories) had no circle. Only a small proportion of cultured pearls in the "no defect" category $(6 \% ; N=7)$ had circles.

Proportions of different pearl shapes were significantly different within the cultured pearl surface defect categories ( $p<0.0001$ ), as shown in figure 4b. Among surface defect categories, B shape and $\mathrm{R}$ shape had very highly significantly different proportions $(p<$ $0.0001)$, while $\mathrm{O}$ shape did not $(p=0.11)$. For B and $\mathrm{R}$ pearl shapes, a gradient appears following the pearl surface quality, from the best surface defect category to the worst: amounts of $\mathrm{R}$ pearls decrease, whereas the amount of B pearls increase. Cultured pearls of the zero defect category had the most in the R category, with $66 \%(N=78)$, the least in the $\mathrm{B}$ category, with $23 \%(N=28)$, and $11 \%(N=13)$ of $\mathrm{O}$ shape. Conversely, the cultured pearls with more than ten defects were made up of $53 \%(N=71) \mathrm{B}$ shape, $37 \%(N=49) \mathrm{R}$ shape and $10 \%(N=13)$ O shape.

\subsection{Relation between cultured pearl lustre and darkness or colour categories}

Two lustre categories were visually classified among the 1342 harvested pearls: those with lustre $(N=1154 ; 86 \%)$ and those without lustre $(N=188,14 \%)$. Within each of these 
two lustre categories, the proportions of the three darkness levels was as follows. For pearls with lustre, $26 \%(N=302)$ of low, $52 \%(N=601)$ of moderate and 22\% $(N=251)$ of high darkness level; for cultured pearls without lustre, $22 \%(N=42)$ of low, $54 \%(N=102)$ of moderate and $24 \%(N=44)$ of high darkness level. These proportions were very highly significantly different within each category $(p<0.0001)$.

Between the two lustre categories, there was no significant differences in the proportions of for low $(p=0.265)$, moderate $(p=0.580)$ or high levels of darkness $(p=0.618)$.

For visual colours of the cultured pearls, the bars in figure 5a show the proportions of the six colour categories within the two lustre categories. Within each of the two lustre categories, very highly significant differences were found among the proportions of the colour categories $(p<0.0001)$. Between the two lustre categories, no significant difference was found for the proportions of pearls with aubergine secondary colour $(p=0.862)$, or with yellow ( $p=0.627$ ) or white $(p=0.386$ ) bodycolors. In contrast, a very highly significant difference $(p<0.0001)$ was recorded for green secondary colour and grey bodycolor between the two lustre categories, and a highly significant difference was recorded for peacock secondary colour $(p=0.0005)$. Green secondary colour pearls represented 58\% $(N=666)$ of pearls with lustre, and grey bodycolor pearls represented $69 \%(N=188)$ of pearls without lustre.

\subsection{Relation between cultured pearl lustre and circle or shape}

Within the two lustre categories, the proportions of the pearls with or without circles were as follows: $26 \%(N=304)$ of the pearls with lustre also had circles and74\% $(N=850)$ had none, while $29 \%(N=54)$ of the pearls without lustre had circles and $71 \%(N=134)$ had none. Comparison within the lustre categories showed a very highly significant difference of in proportions with and without circles in both cases $(p<0.0001)$. Between the two lustre categories, however, no significant difference was found in the proportions of pearls with or without circles $(p=0.494)$.

Figure $5 \mathrm{~b}$ shows the proportions of the three shape categories in the cultured pearl categories with and without lustre. Comparison of cultured pearl shape categories within the lustre groups showed that they have significantly different proportions $(p=0.039)$. Between the two lustre categories, only the B shape category was significantly different, with significantly more B pearls in the category without lustre $(p=0.016)$. No significant difference was found for $\mathrm{R}(p=0.165)$ or O shape $(p=0.120)$. Pearls with lustre had $45 \%(N$ 
$=523)$ of $\mathrm{R}, 42 \%(N=487)$ of $\mathrm{B}$ and $13 \%(N=144)$ of $\mathrm{O}$ shape pearls. Pearls without lustre were composed of $52 \%(N=97)$ of B pearls, $40 \%(N=75)$ of $\mathrm{R}$ and $8 \%$ of $\mathrm{O}(N=16)$ shape pearls. 


\section{Discussion}

The first result of this study was the confirmation of the existence of a highly significant donor family effect for pearl classification grade, surface defects, lustre, darkness level, visual colour categories, circles and shapes, as we had already showed in another experimental graft with other F1 families (Ky et al., 2013). In the same way, significantly different rates of graft retention were again observed here among the fifteen families of donors (data not shown). This finding underlines the determinant role of the graft and suggests a significant genetic donor component for both cultured pearl traits and nucleus retention. It also indicates that improving these traits might be feasible through donor selective breeding (Ky et al., 2013).To date, the interplay of pearl grade and its components with colour (darkness level and visual categories) and shape (circle presence/ absence and shape categories) have never been reported as part of a large experimental graft. Here our results were based on 150 donors and 1342 harvested pearls. This has implications for longterm selective breeding programs. Good knowledge of how economically important traits are correlated with each other is important for limiting the impact of unintended phenotypic effects.

Relations between cultured pearl grade and visual colour categories revealed that grey pearls were the most frequent and represented the largest component of the reject class and the category with the maximum surface defects (> 10 defects) and without lustre, corresponding to nearly $65 \%$ in each case. Conversely, the attractive green secondary colour (and to a lesser extent the peacock colour) shows the largest proportions in the more valuable grade A pearls, the no defect category and in pearls with lustre. The reject class (without any market value) showed the smaller proportion of green overtone pearl colour.

Improvement of cultured pearl quality by selection of appropriate donor "oysters" capable of producing mainly a chosen target colour would be a useful objective for the pearl industry. Such indirect selection is consistent with the work of Wada and Komaru (1996) in which an inbred line of selected white Japanese cultured pearl "oysters", Pinctada fucata martensii, was useful for producing higher quality pearls. For these "akoya" cultured pearls, it would be possible to control the colour, as experimental grafts showed that the frequency of yellow coloured pearls was significantly lower in a group produced by grafting mantle tissue from the white line than from brown lines. For this species, Velayudhan et al. (1995) concluded that it is possible to improve the quality of pearls and nacre thickness through 
selective breeding. Furthermore, Mamangkey (2009; 2010) showed that the colour and the quality of the donor are important for pearl quality improvement in Pinctada maxima.

Recent studies on $P$. margaritifera using controlled experimental grafts have revealed that pearl colour is related to the donor inner shell coloration phenotype (Tayale et al., 2012). The link between the inner shell coloration and the corresponding pearl harvested was clearest for the grey, yellow and white bodycolors. In fact, professional grafters choose not to use "oysters" with a grey band in the inner shell as donors because they observe empirically that the mantle of these pearl "oysters" produces mainly grey pearls(farmers pers. comm.). Tayale et al. (2012) reported a case in their grafting experiment, where a large proportion of yellow cultured pearls (near 60\%) were produced that corresponded to a particular wild donor with a yellow-coloured inner side to its shell. For white pearl production in P. margaritifera, pearl farmers know that using albino variant phenotypes (white shell P. margaritifera) makes it possible to harvest $100 \%$ white pearls (farmers pers. comm.). Indeed, this particular phenotype is characterized by the complete absence of pigment in the shell due to the absence or defect of tyrosinase, an enzyme involved in the production of melanin. In the Federated Sates of Micronesia, careful selection of suitable brood stock capable for blue overtones cultured pearl production has been engaged since 2012 for a specific "Micronesian Blue" product (Cartier et al., 2012).

Darkness level is also related to classification grade and surface defects, but not with lustre. Indeed, in our results, high darkness level was significantly related to both the reject pearl class and poor surface quality ( $>10$ defects). The result reveals also for only darkness level trait (and not for surface defect), that reject class was related to B grade. This seems inconsistent, but it be explain by the data number and the overall effect was confirmed by the fact that surface defect was a component of cultured pearl grade classification. Nacre deposition rate (nacre thickness and weight) would play an indirect role. Indeed, recent studies made by Blay et al. (2014) revealed that: 1) cultured pearls without any surface defect were the thickest and the heaviest, and that 2) cultured pearls with low darkness level were the thinnest and the lightest. By contrast, no relations were found between the paler darkness level groups and pearl grade. Currently, the cultured pearls the most in demand by the pearl market are the darkest ones. The link between shell pigmentation observed in P. margaritifera and the potential to produce light or dark pearls is confirmed by the extreme case discussed above, where the albino variant used as a donor produced light-coloured pearls (100\% white). McGinty's xenograft experiments (2010) show that donor species seems to play a major role 
in the colour of the resulting pearl. In fact, black grafts of $P$. margaritifera implanted in the $P$. maxima (which normally produces golden-coloured cultured pearls) resulted in dark or blackcoloured cultured pearls. Dark tone is known to be linked to the deposition of black pigment, in which melanin and metalloprophyrins have been implicated (Landman et al., 2001, Elen, 2001). The phenotypic observation of many shell colour polymorphisms on several pearl farms suggests this pigmentation to be a continuously varying one, with the involvement of many genes. As a result, pigmentation should be included as quantitative traits in a selective breeding program. Incorporating breeding strategies to fix the putative major gene could dramatically accelerate progress towards developing true-breeding light- or dark-shelled strains of P. margaritifera.

Producing pearls with a green overtone and a lesser proportion of high darkness level would be of great interest for the pearl farming industry to indirectly improve the proportion of grade A pearls. These results open the way for phenotypic selection of pearl "oysters" to serve as donors capable of producing large amounts of grade A pearls. As it is not yet possible to select visually for donor "oysters" with a outer "grade A phenotype", selection of donor "oysters" capable of producing a large amount of green or peacock secondary colours is more realistic; as the inner shell colour of the donor "oyster" is related to the pearl colour (Tayale et al., 2012). Several colour morphs can be observed in P. margaritifera in both the outer (continuous black tone pigmentation) and inner surfaces of the shell. In addition, several compatible and incompatible combinations can be observed between outer and inner shell side. There are a limited number of morph combinations in this species, which suggests that $P$. margaritifera shell pigmentation is under at least partial genetic control, and therefore amenable to artificial selection. Furthermore, distinctive pigment colours or colour patterns in several marine shellfish species have been shown to be controlled by a small number of genes (Evans et al., 2009). Shell and pearl bodycolors of Pinctada sp. have usually been explained by the presence of organic pigments: the colours of the shell and of the resulting pearls differ according to the species, and have been attributed to various different pigments (Iwashawi and Akamatsu,1994, Zhang et al., 2001, 2009, Karampelas et al.,2011). An inventory of the correspondence between outer and inner shell colour combinations and the harvested pearls would make an interesting tool for both pearl farming industry and for genetic selection programs. Indeed, a selection of the animals according to the colour combinations between outer and inner shells would be useful for farming purposes, allowing the breeding of lineages with dominant and predictable colours. In addition, another important benefit of direct 
selection based on outer phenotype of donors is that donor "oysters" can be selected directly and not based on the performance of their progenies.

Until now, no studies have examined the relationships among grade, its components, presence/absence of circles and the shape of cultured pearls. Circles and shape are currently known to be affected by environmental factors, including the surgical operation made by the grafters. In our experiments, animals were managed in homogenous conditions (a single common culture site, the same grafter and receiving pearl "oysters" issued from a single spat collection) to reduce variability due to the environment and to enhance genetic differences. Our results reveal that grade A-B pearls exhibit significantly larger proportions of both uncircled pearls and those that are round in shape than D-reject categories. By contrast, these two last undesirable categories exhibit: 1) the largest proportion of circled pearls (nearly twice as many as in grades A or B) and 2) the most baroque-shaped pearls. This result is interesting, as no obvious link had been established to date between pearl grade and circle/ shape. The possibility of selecting grade A pearls will indirectly correspond to selection of more uncircled and round-shaped pearls. Only a small percentage of cultured pearls will be perfectly round. This is because the eventual shape of the pearl is determined by a number of highly variable processes that occur inside the "oyster", as the pearl is developing. Our results also reveal that cultured pearls with more than five surface defects include a significantly larger proportion of circled pearls and a lesser proportion of round shape pearls. In addition, no clear relationships were seen between lustre and the presence or absence of circles, or between lustre and the valuable round shape. Lustre of pearls is known to be influenced by several environmental factors (Snow et al., 2004), including water temperature and cultural practices, e.g., frequency of animal cleaning, which are believed to produce pearls with maximum lustre. A part of the coloration is also link to these external factors. Further research is underway to determine the influence of environmental effects on pearl quality traits by rearing the grafted "oysters" in different and contrasting farm locations.

Hatchery-based selection and/or production of specific colour donor lines of $P$. margaritifera could therefore also have effects on other cultured pearl quality traits: pearl classification grade, its components, presence/absence of circles and pearl shape. In fact, other experimental grafts using farmed donor families revealed that nacre deposition rate was significantly higher in grade A pearls, which had the thickest and heaviest nacre on average, 
compared with grade D pearls and rejects (Blay et al, 2014). This result is consistent with some of those recorded by Tayale et al. (2012) where, using grafts from wild donors, the authors demonstrated correlations between cultured pearl nacre thickness and grade; the relationship was only found in one out of two grafting trials with wild donors and was not confirmed for nacre weight. Tayale et al. (2012) also showed that nacre thickness and cultured pearl weight in pearls produced using wild donors were correlated with colour components, i.e., darkness levels and visual colour categories, with the palest pearls (i.e., white pearls) being the smallest (lowest thickness and weight). Here, this tendency is confirmed in pearls produced using donors from farmed families. Indeed, some of our results show that the palest pearls (low darkness level) had the thinnest layer of nacre and weighed the least. A good understanding of phenotypic correlations will be necessary to avoid inadvertent selection against non-target traits, such as via the negative correlation observed between nacre deposition rate and lustre that has also been noted in the scientific literature (Alagarswami, 1987b, Snow et al., 2004).

Promising G1 families revealed by experimental grafting could be used as a source of future broodstock for hatchery production. Selection could follow a sib-selection strategy where some individuals from the different donor families would be sacrificed to be used as graft donors. Other members of the same families would be maintained alive in culture and their breeding value determined based on the characteristics of pearls produced by their sibs. Using such a strategy for the P. margaritifera cultured pearls industry in French Polynesia would require the establishment of hatcheries producing selected pearl "oyster" donor lines. It may be possible to reach a point where specific donor lines, producing pearls with specific colours, can be developed and maintained. Farmers wishing to increase their production of pearls of a particular colour would then use individuals from these lines as mantle tissue donors. The development of specialised hatchery-produced donor lines would not affect the socio-economic activity of local wild spat collection dedicated to the production of recipient "oysters" for grafting.

\section{Conclusions}

This is the first study revealing significant phenotypic correlations of cultured pearl grade and its components with colour and shape in P. margaritifera. In fact, grade A pearls can be significantly related to several "indicators": 1) more pearls with the green overtone colour, 2) a lower proportion of pearls with the high darkness level, 3) a large proportion of 
uncircled pearls, and 4) more round pearls. Surface defects, which are one of the two grade classification criteria, show the same significant tendency. In contrast, no evidence was recorded for the second grade component, lustre, in relation to darkness level, circling or roundness, as this is only significantly related to green overtone.

The implications of this work are of a great importance for future work on $P$. margaritifera pearl "oyster" breeding programs. Given the significant correlations observed between grade and colour, directional selection towards "green" donor "oyster" lines could be an important objective for the pearl farming industry. Future work in this area needs to: 1) identify and make a detailed examination of the correspondence between phenotypic pigmentation patterns (linked with the cultured pearl bodycolor) and polymorphism of the donor "oyster" shell and the resulting harvested pearls for genetic selection, and 2) quantify both additive and non-additive genetic effects in order to determine heritability $\left(h^{2}\right)$ values for these pigmentations. Once $h^{2}$ is determined, optimal breeding designs can be developed to obtain the desired pigmentation traits independent of other commercially important performance traits.

\section{Acknowledgements}

This work was supported by grants from the 2013-2014 Convention of the Direction des Ressources Marines et Minières. The authors are also especially thankful for the generous support they received from the host site, Gauguin's Pearl Farm (Rangiroa atoll - Tuamotu Archipelago - French Polynesia). 


\section{References}

Alagarswami, K., 1987. Cultured pearls — production and quality. In: Alagarswami, K. (Ed.), Pearl Culture. Central Marine Fisheries Research Institute, Cochin, India, pp. 107-111.

Blay, C., Sham-Koua, M., Vonau, V., Tetumu, R., Cabral P., Ky, C.L., 2014. Influence of nacre deposition rate on cultured pearl grade and colour in the black lipped pearl oyster Pinctada margaritifera using farmed donor families. Aquaculture International 22, 2, 937-953.

Cartier, E.L., Krzemnicki, M.S., Ito, M., 2012. Cultured pearl farming and production in the Federated States of Micronesia. Gems Gemology 48, 108-122.

Dagnelie, P., 2007. statistique théorique et appliquée, 3rd edn. De Boeck Université, Bruxelles. 734 pp.

Elen, S., 2001. Spectral reflectance and fluorescence characteristics of natural-color and heattreated "golden" south sea cultured pearls. Gems Gemol. 37, 114-123.

Evans, S., Camara, M.D., Langdon, C.J., 2009. Heritability of shell pigmentation in the Pacific oyster, Crassostrea gigas. Aquaculture 286, 211-6.

Hui, B., Vonau, V., Moriceau, J., Tetumu, R., Vanaa, V., Demoy-Schneider, M., Suquet, M., Le Moullac, G., 2011. Hatchery-scale trials using cryopreserved spermatozoa of blacklip pearl oyster (Pinctada margaritifera). Aquat. Living Res. 24, 219-223.

Iwahashi, Y., Akamatsu, S., 1994. Porphyrin pigment in black-lip pearls and its application to pearl identification. Fish. Sci. 60, 1, 69-71.

Karampelas, S., Fritsch, E., Gauthier, J.-P., Hainschwang, T., 2011. UV-Vis-NIR reflectance spectroscopy of natural-color saltwater cultured pearls from Pinctada margaritifera. Gems \& Gemology, Vol 47, 31 - 37.

Ky, C.L., Vergnet, A., Molinari, N., Fauvel, C., Bonhomme, F. 2012. Fitness of early life stages in F1 interspecific hybrids between Dicentrarchus labraxand D. punctatus.Aquatic Living Resources 25, 67-75.

Ky, C.L., Blay, C., Sham-Koua, M., Vanaa, V., Lo, C., Cabral, P., 2013. Family effect on cultured pearl quality in black-lipped pearl oyster Pinctada margaritifera and insights for genetic improvement. Aquatic Living Resources 26, 133-145.

Landman, N.H., Mikkelsen, P.M., Bieler, R., Bronson, B., 2001. Pearls, a natural history. American Museum of Natural History and Harry N. Abrams Inc., New York, pp. 32-54. Le Pennec, M., Anastas, M., Bichet, H., Buestel, D., Cochard, J. C., Cochennec-Laureau, N. , Coeroli, M., Conte, E., Correia, P., Fougerousse-Tsing, A., Langy, S., Le Moullac, G., 
Lo, C., Peltzer, L., Pham. A., 2010. Huître perlière et perle de Tahiti.Faaa, French Polynesia: HQ Imaging. 204 pp.

Mamangkey, N. G. F., Agatonovic, S., Southgate, P. C., 2010. Assessing pearl quality using reflectance UV-Vis spectroscopy: does the same donor produce consistent pearl quality, Marine Drugs, 8, 2517-2525.

McGinty, E.L., Evans, B.S., Taylor, J.U.U., Jerry, D.R., 2010. Xenografts and pearl production in two pearl oyster species, $P$. maxima and P. margaritifera: effect on pearl quality and a key to understanding genetic contribution. Aquaculture302, 175-181.

Siegel, S., Castellan, N.J., 1988. Nonparametric statistics for the behavioral sciences, second edition, McGraw-Hill, New-York, pp. 399.

Snow, M.R., Pring, A., Self, P., Losic, D., Shapter, J., 2004. The origin of the color of pearls in iridescence from nano-composite structures of the nacre. Am. Mineral. 89, 13531358.

Tayale, A., Gueguen, Y., Treguier, C., Le Grand, J., Cochennec-Laureau, N., Montagnani, C., Ky,C.L., 2012. Evidence of donor effect on cultured pearl quality from a duplicated grafting experiment on Pinctada margaritifera using wild donors. Aquatic Living Resources 25, 269-280.

Velayudan, T.S., Chellam, A., Dharmaraj, S., Victor, A.C.C., Kasim, H.M., 1996.

Comparison of growth and shell attributes for four generations of pearl oyster Pinctada fucata (Gould) produced in the hatchery. Indian Journal of Fisheries43, 69-77.

Wada, K.T., 1984. Breeding study of the pearl oyster Pinctada fucata. Bull. Natl. Res. Inst. Aquaculture6, 79-157.

Wada, K.T., 1986. Genetic selection for shell traits in the Japanese pearl oyster, Pinctada fucata martensii. Aquaculture57, 171-176.

Wada, K.T., Komaru, A., 1996. Color and weight of pearls produced by grafting the mantle tissue from a selected population for white shell color of the Japanese pearl oyster Pinctada fucata martensii (Dunker). Aquaculture 142, 25-32.

Wane, G., 1993. Les problèmes réels de l'industrie de la perle de Tahiti, Tahiti Pacifique, mensuel d'information et d'économie, 260, 15-24.

Winer, B.J., Brown, D.R., Michels, K.M., 1991. Statistical principles in experimental design, McGraw-Hill, New-York.

Zhang, G., Xie, X., Wang, Y., 2001. Raman spectra of nacre from shells of main pearlculturing mollusks in China. Spectrosc. Spectr. Anal. 21, 193-196. 
Fig. 1. Cultured pearl darkness distribution (expressed in $\%$ of each of the following categories: low, moderate and high darkness) from each classification grade (A, B, C, D and reject, according to the Tahitian Classification) (a), cultured pearl colour distribution (expressed in \% of each of the following visual categories (bodycolor: grey, white, yellow; secondary colour: aubergine, green, peacock) from each classification grade (A, B, C, D and Reject) (b). The data points significantly different at $p<0.05$ are indicated with letters between the cultured pearl grade.

a.

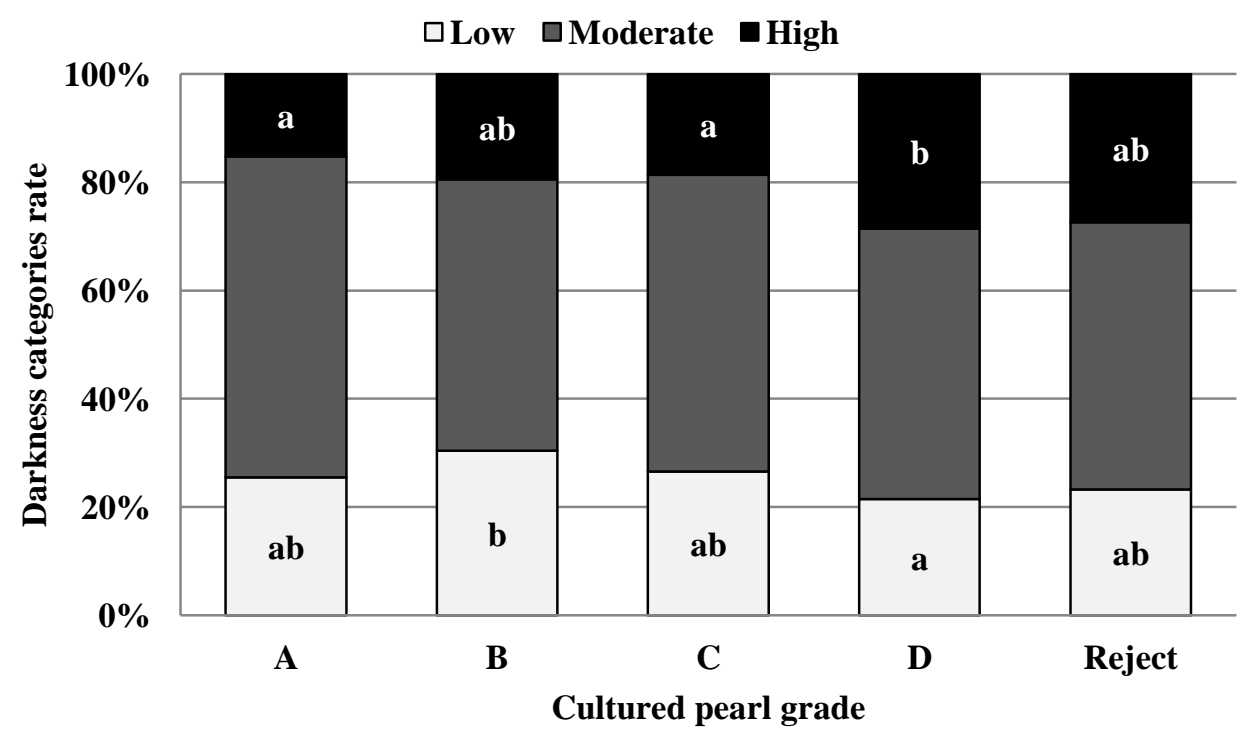

b.

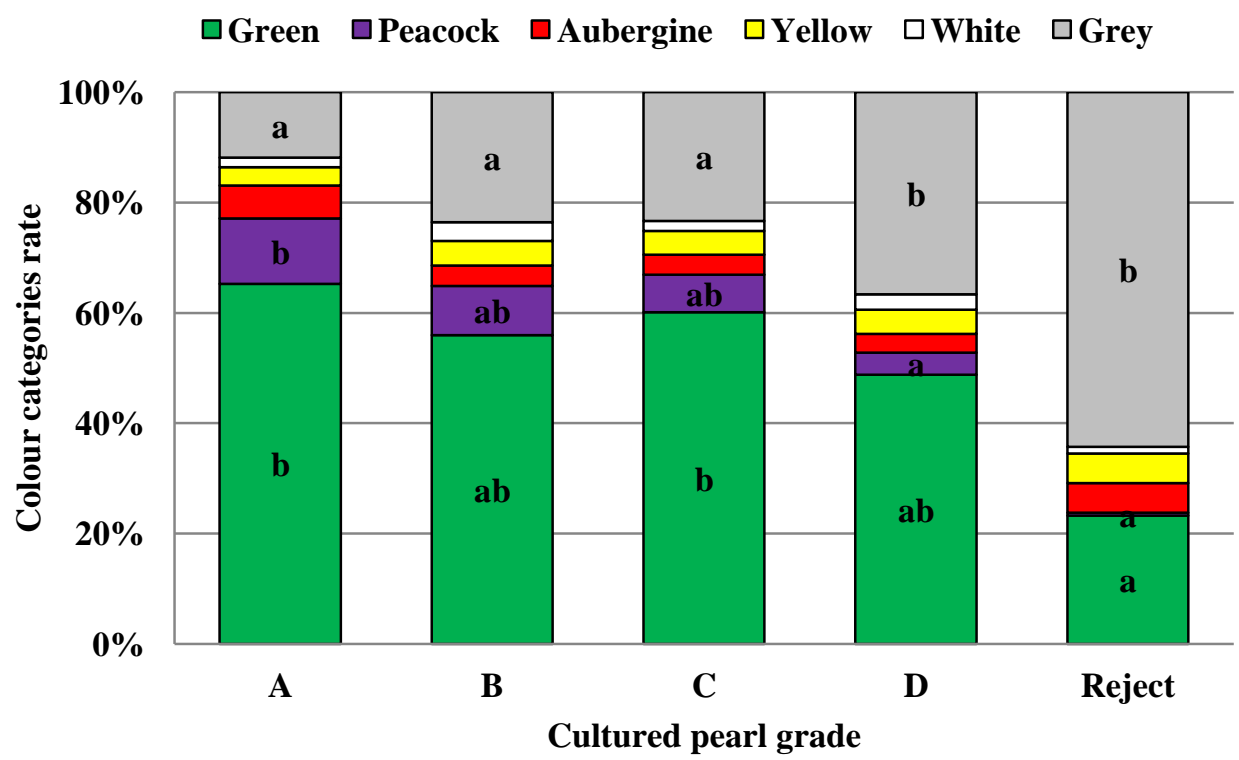


Fig. 2. Cultured pearl circle distribution (expressed in \% of pearls with and without circles) in each cultured pearl classification grade (grades A, B, C, D and Reject, according to the Tahitian Classification) (a). Cultured pearl shape distribution (expressed in \%) between the three following categories: 1) "B" shape (baroque and semi-baroque); 2) "O" shape (oval, drop and button); 3) "R" shape (round or semi-round) from each classification grade (grades A, B, C, D and reject) (b). The data points significantly different at $p<0.05$ are indicated with letters between the cultured pearl grade.

a.

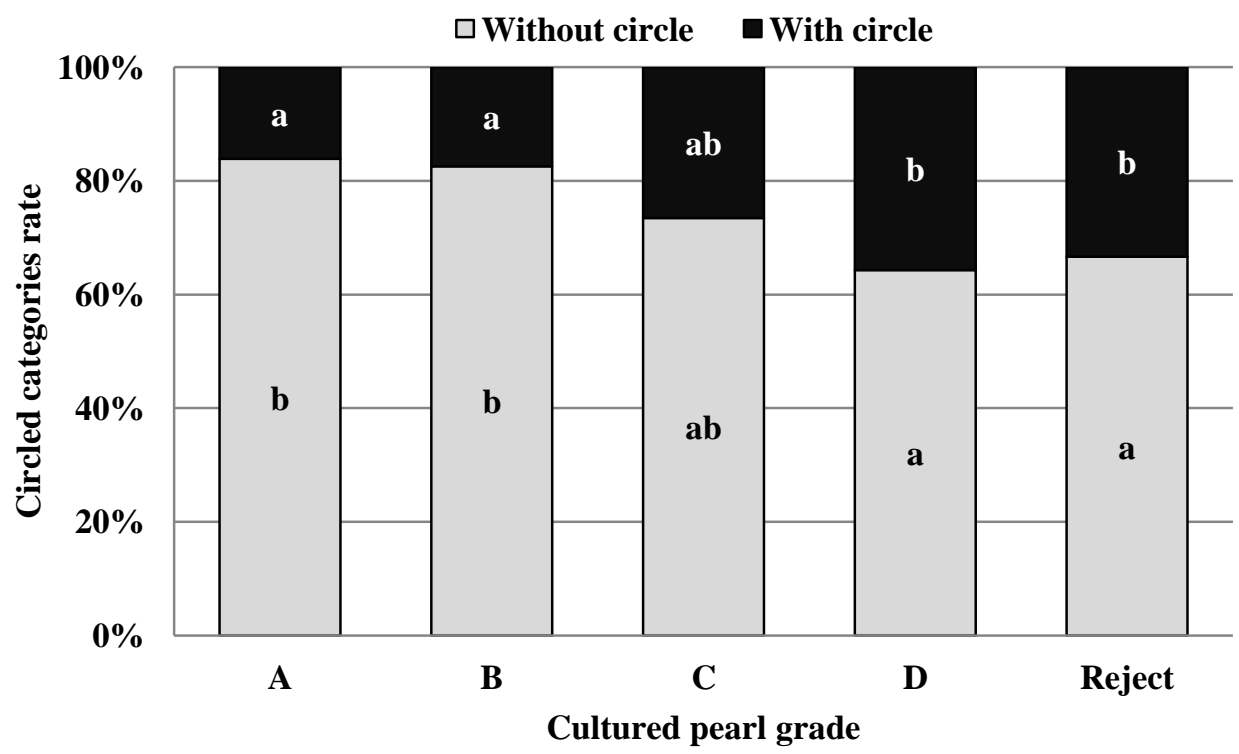

b.

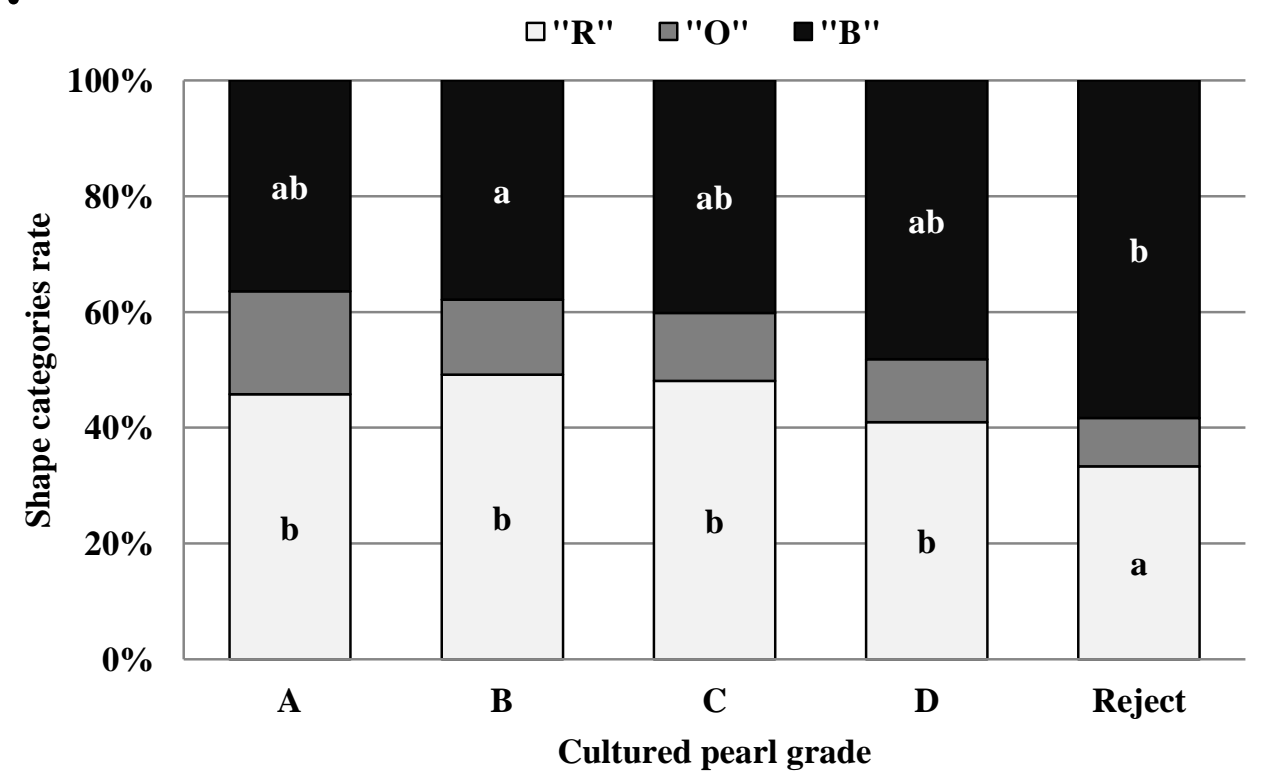


Fig. 3. Cultured pearl darkness distribution (expressed in $\%$ of each of the following categories: low, moderate and high darkness) from each surface defect category: no defects, 1 to 5 defects, 6 to 10 defects and over 10 defects (a). Cultured pearl "colour categories" distribution (\% of each of the following categories: peacock, aubergine, green, yellow, white and grey) from each surface defect category: no defects, 1 to 5 defects, 6 to 10 defects and over 10 defects (b). The data points significantly different at $p<0.05$ are indicated with letters between the pearl surface defect.

a.

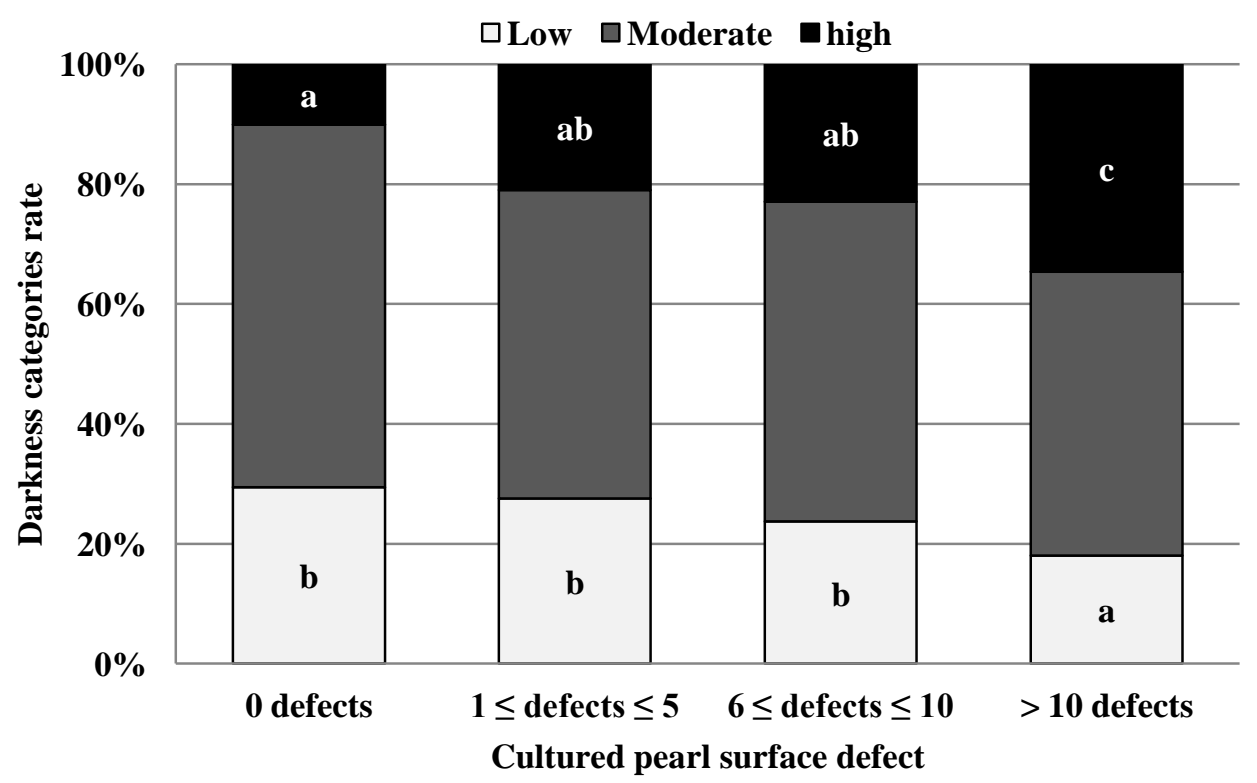

b.

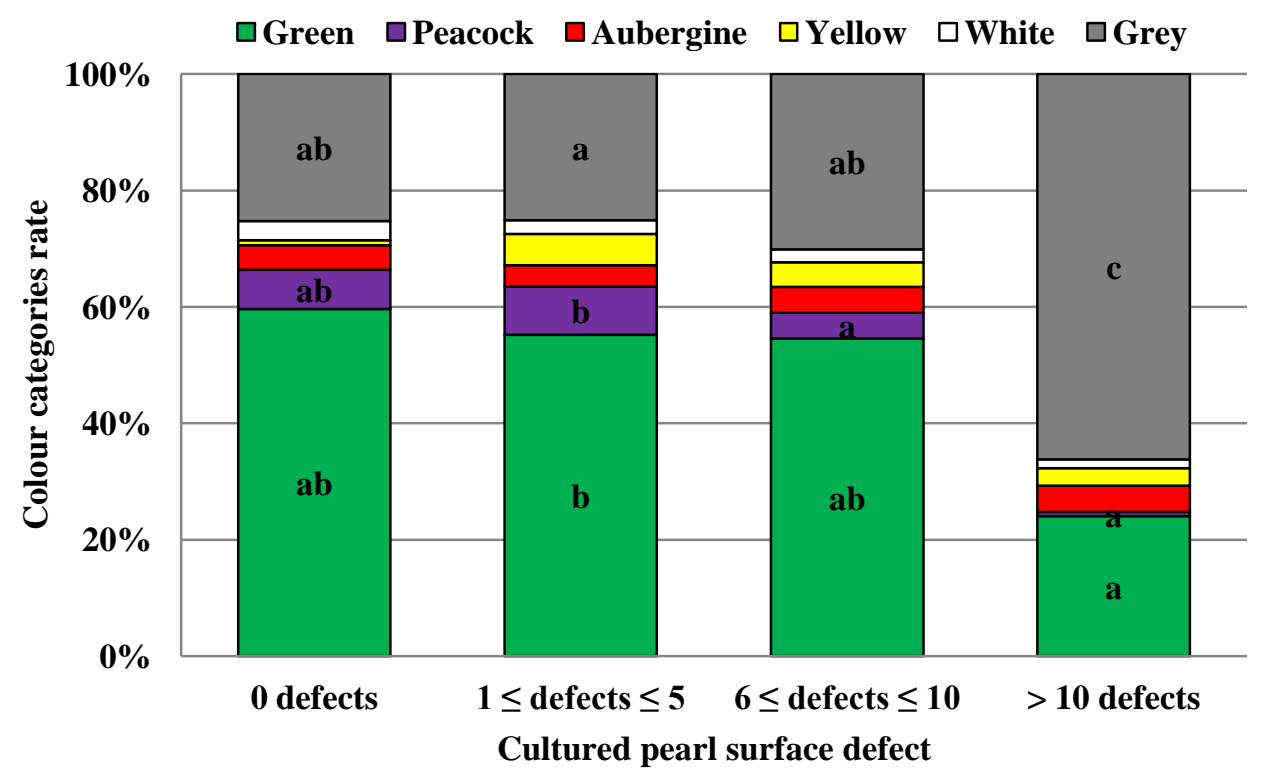


Fig. 4. Cultured pearl circle proportion (expressed in $\%$ of pearls with and without circled) in each surface defect category (no defect, 1 to 5 defects, 6 to 10 defects and up to 10 defects) (a). Cultured pearl shape proportion (expressed in \%) in the three following categories: "B" shape (baroque and semi-baroque), "O" shape (oval, drop and button) and "R" shape (round or semi-round) from each surface defect category: no defects, 1 to 5 defects, 6 to 10 defects and up to defects (b). The data points significantly different at $p<0.05$ are indicated with letters between the pearl surface defect.

a.

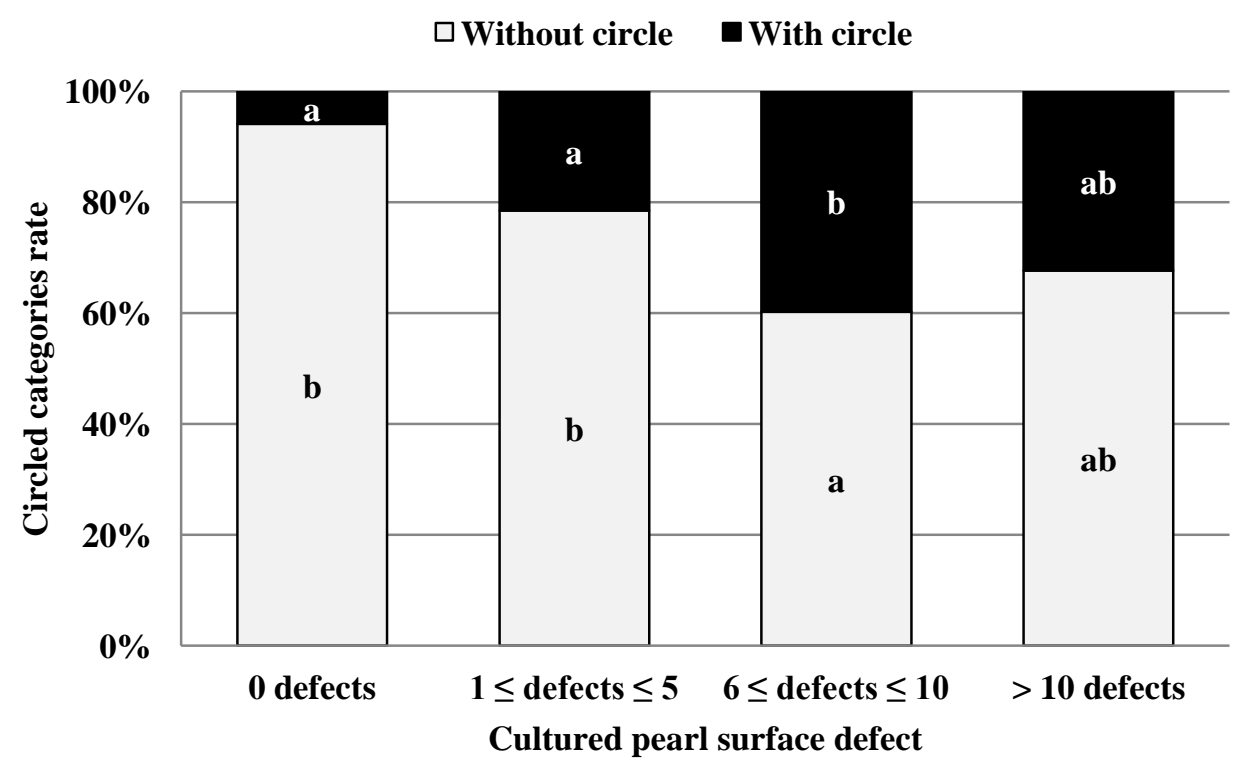

b.

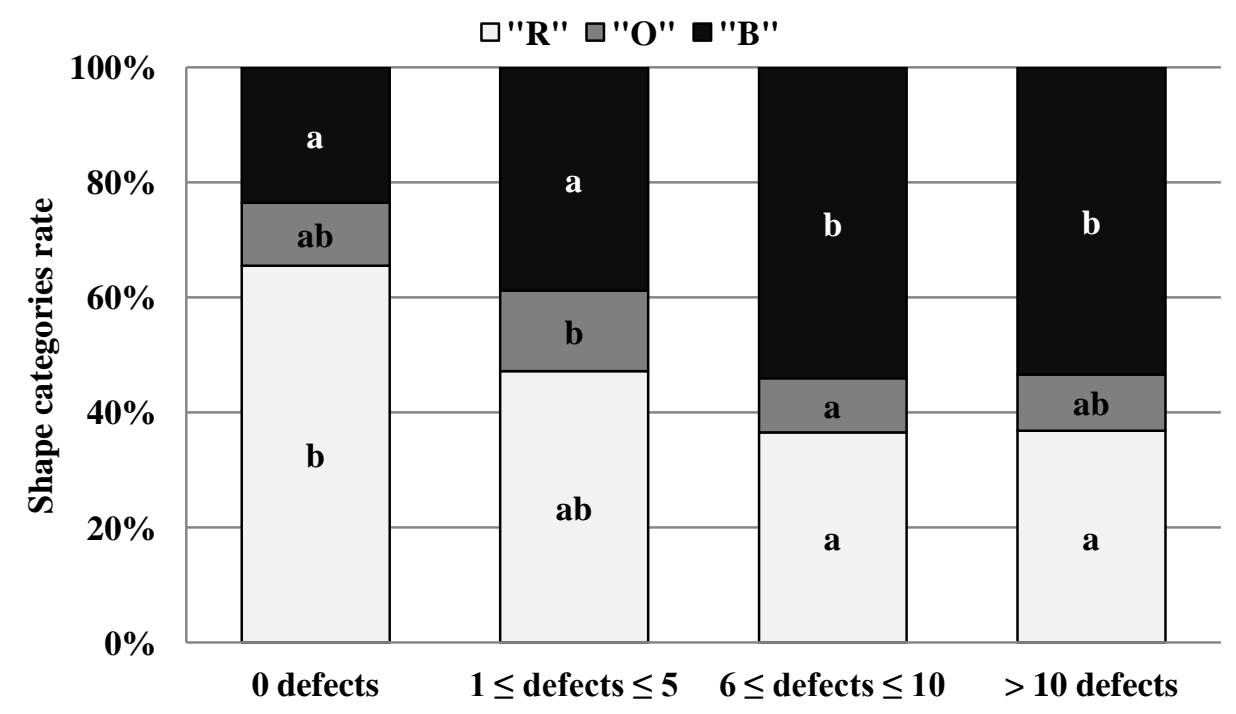

Cultured pearl surface defect 
Fig. 5. Cultured pearl colour distribution (\% of each of the following categories: peacock, aubergine, green, yellow, white and grey) for pearls with or without lustre (a). Cultured pearl shapes (expressed in \%) in the three following categories: 1) "B" shape (baroque and semi-baroque); 2) "O" shape (oval, drop and button); 3) "R" shape (round or semi-round) for presence or absence of lustre category (b). The data points significantly different at $p<0.05$ are indicated with letters between the pearl lustre categories.

a.

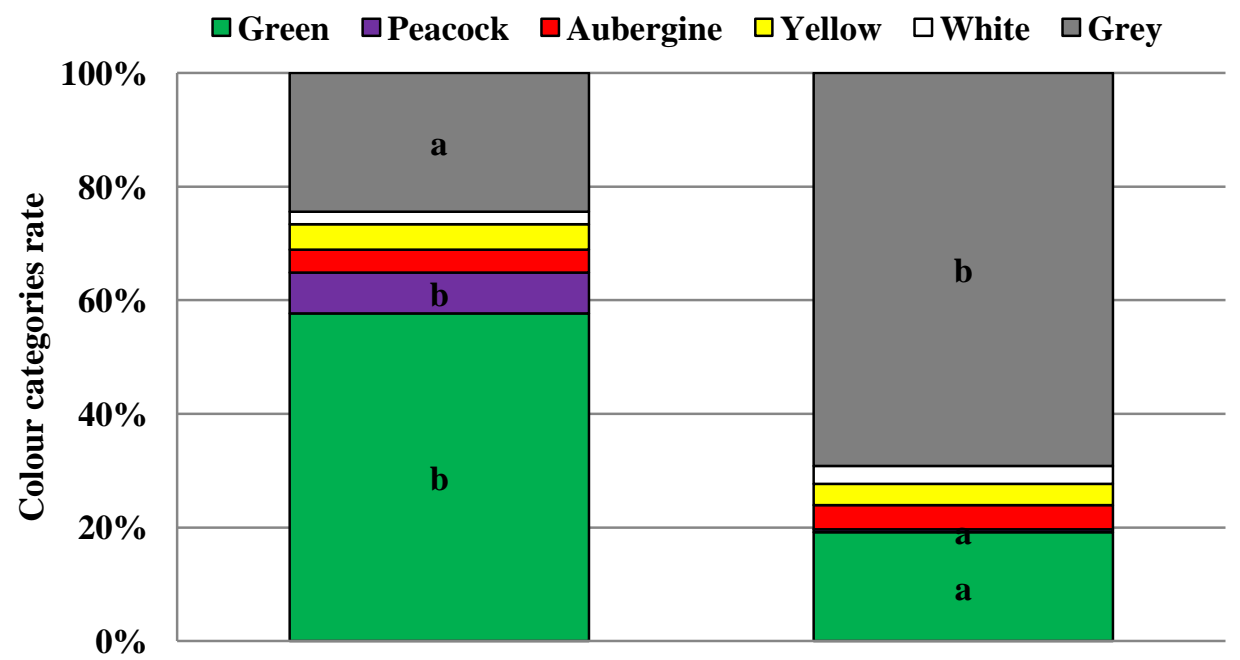

With lustre

Without lustre

Cultured pearl lustre

b.

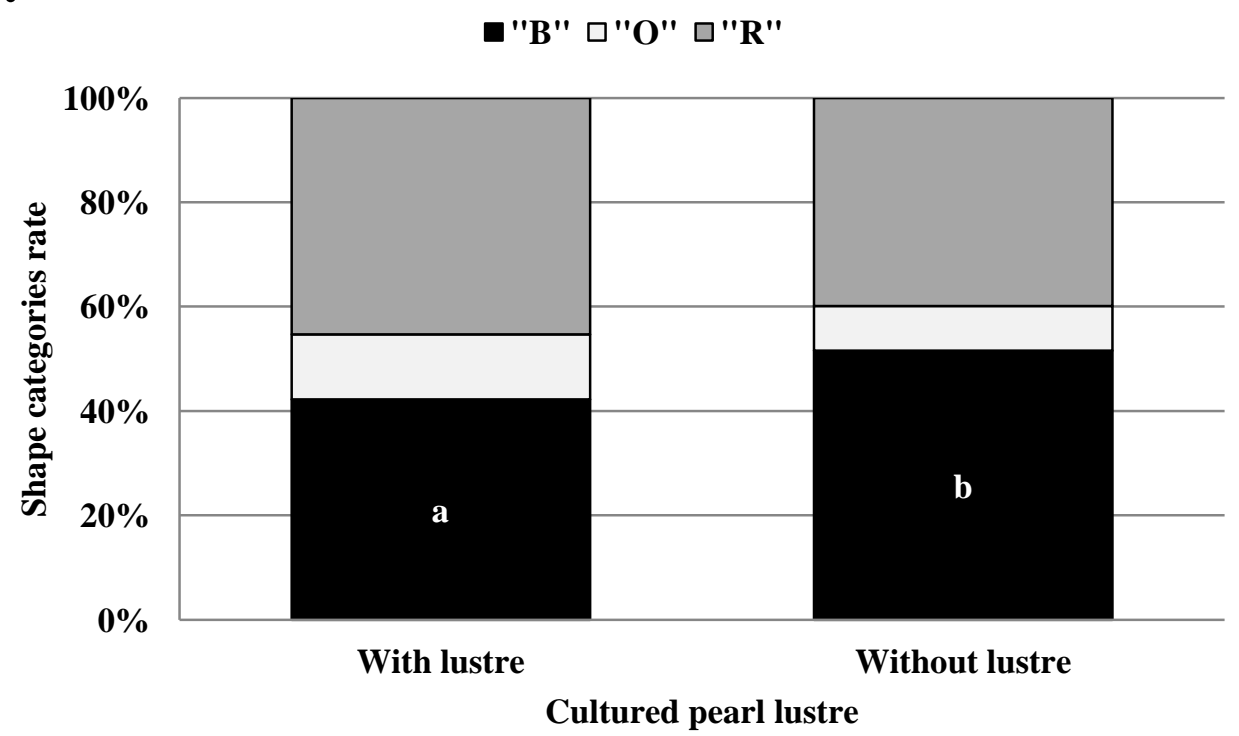


Table 1:Classification grade(A, B, C, D and Reject), surface defects (0: no defects; 1: 1 to 5 defects; 2: 6 to 10 defects and 3: more than 10 defects), lustre (1: with or 0: without lustre), visual colour categories, (bodycolor: GY: grey, W: white, Y: yellow; secondary colour:GR: green,P: peacock, A: aubergine), darkness level (L: low, M: moderate and D: high darkness), circle (1: presence or 0: absence) and shape categories ("B" shape: baroque and semi-baroque; "O" shape: oval, drop and button and "R" shape, round or semi-round) of cultured pearlsproduced from 15 families of graft donor oysters (family 1 to 15). The first entry in each cell indicates the percentage contribution (\%) for of each of the quality trait categories in a particular family. The second entry (in brackets) corresponds to the number of pearls observed in this category. 


\begin{tabular}{|c|c|c|c|c|c|c|c|c|c|c|c|c|c|c|c|c|c|c|c|c|c|c|c|c|c|}
\hline \multirow{2}{*}{ Family } & \multicolumn{5}{|c|}{ Grade } & \multicolumn{4}{|c|}{ Surface defect } & \multicolumn{2}{|c|}{ Lustre } & \multicolumn{6}{|c|}{ Colour } & \multicolumn{3}{|c|}{ Darkness } & \multicolumn{2}{|c|}{ Circle } & \multicolumn{3}{|c|}{ Shape } \\
\hline & $A$ & B & C & $\mathrm{D}$ & $\mathrm{R}$ & 0 & 1 & 2 & 3 & 0 & 1 & GN & $\mathrm{P}$ & $A$ & GY & Y & W & $D$ & $\mathrm{M}$ & $\mathrm{L}$ & 0 & 1 & $r$ & $b$ & 0 \\
\hline \multirow[t]{2}{*}{1} & 12.4 & 36.0 & 27.0 & 12.4 & 12.4 & 16.9 & 61.8 & 16.9 & 4.5 & 23.6 & 76.4 & 21.3 & 4.5 & 12.4 & 52.8 & 7.9 & 1.1 & 2.2 & 75.3 & 22.5 & 75.3 & 24.7 & 33.7 & 53.9 & 12.4 \\
\hline & (11) & (32) & (24) & (11) & (11) & (15) & (55) & (15) & (4) & (21) & (68) & (19) & (4) & (11) & (47) & (7) & (1) & (2) & (67) & (20) & (67) & (22) & (30) & (78) & (11) \\
\hline \multirow[t]{2}{*}{2} & 20.0 & 22.2 & 24.4 & 20.0 & 13.3 & 20.0 & 52.2 & 17.8 & 10.0 & 15.6 & 84.4 & 41.1 & 4.4 & 0.0 & 50.0 & 0.0 & 4.4 & 18.9 & 57.8 & 23.3 & 83.3 & 16.7 & 36.7 & 46.7 & 16.7 \\
\hline & (18) & (20) & (22) & (18) & (12) & (18) & (47) & (16) & (9) & (14) & (76) & (37) & (4) & (1) & (45) & (0) & (4) & (17) & (52) & (21) & (75) & (15) & (33) & (42) & (15) \\
\hline \multirow[t]{2}{*}{3} & 10.1 & 25.3 & 32.3 & 22.2 & 10.1 & 11.1 & 56.6 & 25.3 & 7.1 & 8.1 & 91.9 & 59.6 & 3.0 & 12.1 & 21.2 & 4.0 & 0.0 & 9.1 & 48.5 & 42.4 & 69.7 & 30.3 & 44.4 & 47.5 & 8.1 \\
\hline & (10) & (25) & (32) & (22) & (10) & (11) & (56) & (25) & (7) & (8) & (91) & (59) & (3) & (12) & (21) & (4) & (0) & (9) & (48) & (42) & (69) & (30) & (44) & (47) & (8) \\
\hline \multirow[t]{2}{*}{4} & 8.3 & 18.8 & 39.6 & 25.0 & 8.3 & 4.2 & 51.0 & 40.6 & 4.2 & 13.5 & 86.5 & 44.8 & 8.3 & 8.3 & 30.2 & 8.3 & 0.0 & 12.5 & 47.9 & 39.6 & 55.2 & 44.8 & 34.4 & 51.0 & 14.6 \\
\hline & (8) & (18) & (38) & (24) & (8) & (4) & (49) & (39) & (4) & (13) & (83) & (43) & (8) & (8) & (29) & (8) & (0) & (12) & (46) & (38) & (53) & (43) & (33) & (49) & (14) \\
\hline \multirow[t]{2}{*}{5} & 18.1 & 18.1 & 30.9 & 20.2 & 12.8 & 9.6 & 56.4 & 27.7 & 6.4 & 11.7 & 88.3 & 59.6 & 6.4 & 8.5 & 22.3 & 3.2 & 0.0 & 20.2 & 59.6 & 20.2 & 57.4 & 42.6 & 50.0 & 37.2 & 12.8 \\
\hline & (17) & (17) & (29) & (19) & (12) & (9) & (53) & (26) & (6) & (11) & (83) & (56) & (6) & (8) & (21) & (3) & (0) & (19) & (56) & (19) & (54) & (40) & (47) & (35) & (12) \\
\hline \multirow[t]{2}{*}{6} & 14.0 & 17.0 & 22.0 & 25.0 & 22.0 & 22.0 & 46.0 & 20.0 & 12.0 & 23.0 & 77.0 & 55.0 & 0.0 & 0.0 & 44.0 & 0.0 & 1.0 & 33.0 & 51.0 & 16.0 & 74.0 & 26.0 & 54.0 & 39.0 & 7.0 \\
\hline & (14) & (17) & (22) & (25) & (22) & (22) & (46) & (20) & (12) & (23) & (77) & (55) & (0) & (0) & (44) & (0) & (1) & (33) & (51) & (16) & (74) & (26) & (54) & (39) & (7) \\
\hline \multirow[t]{2}{*}{7} & 8.3 & 16.7 & 40.0 & 20.0 & 15.0 & 0.0 & 45.0 & 45.0 & 10.0 & 3.3 & 96.7 & 70.0 & 8.3 & 0.0 & 16.7 & 1.7 & 3.3 & 8.3 & 60.0 & 31.7 & 85.0 & 15.0 & 45.0 & 50.0 & 5.0 \\
\hline & (5) & (10) & (24) & (12) & (9) & (0) & (27) & (27) & (6) & (2) & (58) & (42) & (5) & (0) & (10) & (1) & (2) & (5) & (36) & (19) & (51) & (9) & (27) & (30) & (3) \\
\hline \multirow[t]{2}{*}{8} & 5.2 & 20.8 & 28.6 & 35.1 & 10.4 & 6.5 & 41.6 & 37.7 & 14.3 & 5.2 & 94.8 & 59.7 & 0.0 & 0.0 & 39.0 & 1.3 & 0.0 & 26.0 & 50.6 & 23.4 & 72.7 & 27.3 & 48.1 & 39.0 & 13.0 \\
\hline & (4) & (16) & (22) & (27) & (8) & (5) & (32) & (29) & (11) & (4) & (73) & (46) & (0) & (0) & (30) & (1) & (0) & (20) & (39) & (18) & (56) & (21) & (37) & (30) & (10) \\
\hline \multirow[t]{2}{*}{9} & 1.9 & 11.7 & 41.7 & 37.9 & 6.8 & 4.9 & 40.8 & 47.6 & & 4.9 & 95.1 & 63.1 & 12.6 & 8.7 & 12.6 & 1.0 & 1.9 & 33.0 & 49.5 & 17.5 & 75.7 & 24.3 & 56.3 & 32.0 & 11.7 \\
\hline & (2) & (12) & (43) & (39) & (7) & (5) & (42) & (49) & (7) & (5) & (98) & (35) & (13) & (9) & (13) & (1) & (2) & (34) & (51) & (18) & (78) & (25) & (58) & (33) & (12) \\
\hline \multirow[t]{2}{*}{10} & 2.3 & 16.1 & 42.5 & 16.1 & 23.0 & 3.4 & 49.4 & 31.0 & 16.1 & 28.7 & 71.3 & 47.1 & 5.7 & 0.0 & 32.2 & 13.8 & 1.1 & 25.3 & 58.6 & 16.1 & 75.9 & 24.1 & 44.8 & 36.8 & 18.4 \\
\hline & (2) & (14) & (37) & (14 & (20) & (3) & (43) & (27) & (14) & (25) & (62) & (41) & (5) & (0) & (28) & (12) & (1) & (22) & (51) & (14) & (66) & (21) & (39) & (32) & (16) \\
\hline \multirow[t]{2}{*}{11} & 8.8 & 25.3 & 41.8 & 14.3 & 9.9 & 6.6 & 64.8 & 22.0 & 6.6 & 9.9 & 90.1 & 61.5 & 13.2 & 2.2 & 17.6 & 4.4 & 1.1 & 36.3 & 33.0 & 30.8 & 81.3 & 18.7 & 36.3 & 46.2 & 17.6 \\
\hline & (8) & (23) & (38) & (13) & (9) & (6) & (59) & (20) & (6) & (9) & (82) & (56) & (12) & (2) & (16) & (4) & (1) & (33) & (30) & (28) & (74) & (17) & (33) & (42) & (16) \\
\hline \multirow[t]{2}{*}{12} & 6.3 & 27.8 & 27.8 & 25.3 & 12.7 & 3.8 & 49.4 & 32.9 & 13.9 & 15.2 & 84.8 & 64.6 & 1.3 & 0.0 & 25.3 & 6.3 & 2.5 & 25.3 & 48.1 & 26.6 & 70.9 & 29.1 & 34.2 & 50.6 & 15.2 \\
\hline & (5) & (22) & (22) & (20) & (10) & (3) & (39) & (26) & (11) & (12) & (67) & (51) & (1) & (0) & (20) & (5) & (2) & (20) & (38) & (21) & (56) & (23) & (27) & (40) & (12) \\
\hline \multirow[t]{2}{*}{13} & 0.0 & 15.3 & 36.5 & 38.8 & 9.4 & 4.7 & 43.5 & 32.9 & 18.8 & 11.8 & 88.2 & 49.4 & 9.4 & 4.7 & 30.6 & 4.7 & 1.2 & 32.9 & 54.1 & 12.9 & 72.9 & 27.1 & 57.6 & 31.8 & 10.6 \\
\hline & (0) & (13) & (31) & (33) & (8) & (4) & (37) & (28) & (16) & (10) & (75) & (42) & (8) & (4) & (26) & (4) & (1) & (28) & (46) & (11) & (62) & (23) & (49) & (27) & (9) \\
\hline
\end{tabular}


14

$\begin{array}{lllllllllllllllll}13.0 & 37.0 & 23.9 & 20.7 & 5.4 & 12.0 & 56.5 & 27.2 & 4.3 & 10.9 & 89.1 & 40.2 & 9.8 & 0.0 & 25.0 & 7.6 & 17.4\end{array}$

$\begin{array}{llllllllllllllllll}(12) & (34) & (22) & (19) & (5) & (11) & (52) & (25) & (4) & (10) & (82) & \text { (37) } & \text { (9) } & \text { (0) } & \text { (23) } & \text { (7) } & \text { (16) }\end{array}$

15

$\begin{array}{lllllllllllllllll}2.0 & 20.0 & 35.0 & 26.0 & 17.0 & 3.0 & 48.0 & 33.0 & 16.0 & 21.0 & 79.0 & 53.0 & 6.0 & 0.0 & 39.0 & 2.0 & 0.0\end{array}$

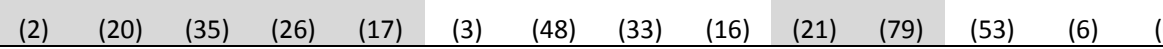

(39) 